\title{
Cross-species surveillance and risk factors associated with Avian Coronavirus in North-Central and South West Regions of Nigeria
}

\author{
Daodu, O.B. ${ }^{1 *}$, Jokotola, P.T. ${ }^{1}$, Omowon, A.A. ${ }^{2}$, Olorunshola, I.D. ${ }^{1}$, Ahmed, O.A. ${ }^{1}$, Raufu, I.A. ${ }^{1}$, \\ Raji, M.A. ${ }^{1}$, Daodu, O.C. ${ }^{3}$ \\ ${ }^{1}$ Department of Veterinary Microbiology, Faculty of Veterinary Medicine, University of Ilorin, PMB 1515, Ilorin, Kwara State, Nigeria \\ ${ }^{2}$ Department of Animal Health Technology, School of Animal and Fisheries Technology, Oyo State College of Agriculture and Technology, Igboora, \\ Oyo State, Nigeria \\ ${ }^{3}$ Department of Wildlife and Ecotourism, Faculty of Agriculture, University of Ibadan, Ibadan, Oyo State, Nigeria \\ *Corresponding author: daodu.femi@gmail.com; daodu.ob@unilorin.edu.ng
}

\section{ARTICLE HISTORY}

Received: 6 July 2020

Revised: 19 October 2020

Accepted: 20 October 2020

Published: 25 March 2021

\begin{abstract}
Infectious bronchitis viral (IBV) (Avian coronavirus) diseases is among the major reproductive diseases affecting the avian production in Africa. There is scanty information on its current status and vaccination compliance among captive wild birds (CWB) and indigenous chickens (LC) in Nigeria. This study aimed to assess the exposure and the risk factors associated with IBV in CWB and LC from North-central and South west regions of Nigeria. Sera samples from 218 LC and 43 CWB were examined for IBV IgG using enzyme linked immunosorbent assay. Also, owners of LC and managers of CWB were interviewed using a pre-tested structured checklist. An overall IBV prevalence of $42.9 \%$ (112/261) was obtained. Captive wild birds and indigenous chickens had $11.6 \%(5 / 43)$ and $49.1 \%$ (107/218) prevalence respectively with a significant difference $(p<0.0001, O R=7.3,95 \% \mathrm{Cl}=2.8-19.3)$. Also, geo-location indicated significant difference in IBV exposure among birds $(p \leq 0.034)$. Furthermore, the study showed that there had never been laboratory screening on all acquired wild birds for exposure to infectious agents in the study location while none of these birds (LB/CWB) had history of vaccination. Since IBV is endemic in Nigeria, the use of vaccine for prophylactic measure should be advocated among LC and CWB owners in order to avoid unnecessary losses. Also, the essence of screening for infectious agents in newly acquired wild birds should be considered crucial for health sustenance and public safety.
\end{abstract}

Keywords: Infectious bronchitis virus, wild birds, local chicken, ELISA, prevalence, vaccination, Nigeria.

\section{INTRODUCTION}

Avian coronavirus was first reported in North Dakota, USA and named as Infectious bronchitis virus (IBV) in 1930 to explain the major clinicopathological characteristics of a transmissible respiratory and reproductive disease of poultry (MacLachlan \& Dubovi, 2011; Jackwood, 2019). IBV is a member of the family Coronaviridae where severe acute respiratory syndrome coronavirus (SARS-CoV-1), SARS-CoV-2 (COVID-19), Bovine CoV, Turkey CoV, Feline CoV, Bat CoV HKU3 and Human $\mathrm{CoV}$ belonged. The viral genome is infectious and is made up of the largest single molecule of linear positive-sense single-stranded RNA (Milek \& Blicharz-Domanska, 2018). Mutations in their genome result into the existence of several antigenic variants and serotypes (Woo et al., 2009; MacLachlan \& Dubovi, 2011).

Several birds' species (domesticated and wild birds) are known to be susceptible to IBV (MacLachlan \& Dubovi, 2011). Generally, birds can become infected through aerosol and or ingestion of faecal-contaminated feed. IBV is known to survive in the environment (fomite and soil) for several days. However, their enveloped structure makes it susceptible to common disinfectants.

The clinical presentation and severity of IBV in birds seem to depend on several factors such as bird's factors (age, genetic background, immune status at the time of infection, exposure route, nutrition especially calcium level in the feed), viral factor (viral virulence) and environmental factors (low temperature, presence of secondary infections). IBV incubation period is $18-48$ hours and mortality rate could be as high as $30 \%$ but sometimes could be more in young chicks (MacLachlan \& Dubovi, 2011). Several reproductive mishap is known to be precipitated by IBV and this usually result into huge financial losses during and after recovery. Infected young female chicks was reported to have permanent hypoplasia of the oviduct which later result into low egg production and poor egg quality during laying stage. In addition, young layers infected by IBV are reported to 
likely show drop or cessation in egg production immediately post-infection but later found not reaching peak in egg production. Meanwhile, layer bird that is yet to reach such peak prior to infection may never do so post-recovery. Generally, infected layers after recovery produces abnormal eggs which may include shell-less egg, thin shell, shells with ridges, stipples, dimples and discoloured eggs (Jackwood, 2019; MacLachlan \& Dubovi, 2011). Persistent infection especially among some flocks (up to 20 weeks postinfection in chickens) with continuous emergence of antigenic variants appears to make IBV control difficult (MacLachlan \& Dubovi, 2011). Furthermore, the challenges of poor reproductive efficiency among captive wild birds persist especially in facilities where breeding is targeted in Nigeria.

This study aimed to determine the extent of IBV exposure among captive wild birds and Nigerian indigenous (local) chickens in Nigeria.

\section{MATERIALS AND METHOD}

\section{Ethical approval}

All applicable international, national, and/or institutional guidelines for the care and use of animals were duly followed. Samples were only obtained from birds after owner's consent.

\section{Study locations and sites}

The local chickens were randomly obtained from markets and rural communities in Kwara, Osun and Oyo States of Nigeria (Figure 1) while wild birds were obtained from zoos, private menageries and resorts. These study locations are within tropical rain forest and guinea savannah vegetations of North central and South-west regions of Nigeria.
Bird selection, Sample collection and processing

Apparently healthy local chickens and captive wild birds were randomly selected. Captive wild birds that had resided in the captive for 1 year and above and those that were hatched within the captive were selected for this study. Also, only local chickens raised in the study sites were selected.

Depending on the bird's weight $(0.8 \mathrm{ml} / \mathrm{kg}), 1-3 \mathrm{ml}$ of blood were collected and dispensed into plain tube. The blood was transported to the Microbiology laboratory of the University of Ilorin Veterinary Teaching Hospital under cold chain and left for 1 hour before centrifugation at 2500rpm for 10 minutes. The serum was then separated into $2 \mathrm{ml}$ cryovial tube and stored at $-20^{\circ} \mathrm{C}$ until analysis.

\section{Interview and distance observations}

Local chicken owners and managers of zoo, private menageries and resort were interviewed on the system of management, vaccination history, experience (egg production, morbidity, mortality), quarantine and screening of wild birds before introduction into the flock, access by other animal (captive wild birds).

\section{Indirect Enzyme immunoassay}

Immunoglobin $\mathrm{G}$ against infectious bronchitis virus were assayed using commercial enzyme linked immunosorbent assay kit (BioCheck, UK). The assay was carried out based on the manufacturer's instruction. Briefly, $100 \mu$ l of 1:500 diluted sera samples were each dispensed into microplate wells coated with IBV antigen. Also, $100 \mu$ l each of positive (serum containing specific IgG to IBV) and negative controls (serum of specific pathogen free chicken) were dispensed into the wells. The plate was left to incubate at $27^{\circ} \mathrm{C}$ for 30 minutes. The well content was discarded, washed with $300 \mu \mathrm{l} /$ well for

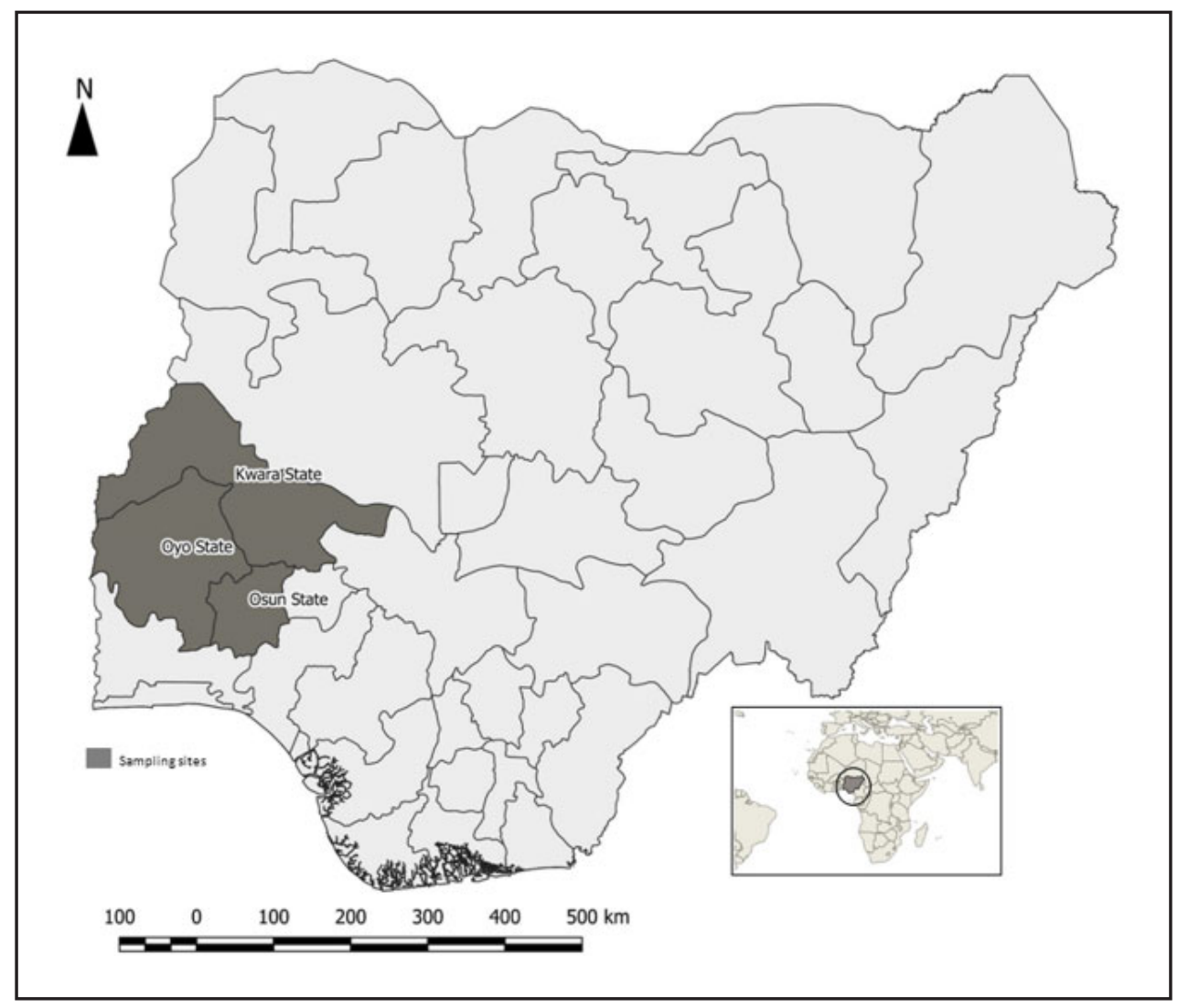

Figure 1. Map of Kwara, Osun and Oyo States of Nigeria where local chickens and captive wild birds were obtained. 
4 times and then tapped firmly on absorbent paper. This was followed by the addition of $100 \mu \mathrm{l} /$ well of conjugate (Sheep anti-chicken antibody with Alkaline phosphatase) and the plate was left to incubate for 30 minutes at $27^{\circ} \mathrm{C}$. The washing step was repeated before the addition of $100 \mu \mathrm{l}$ of substrate ( $p$-Nitrophenyl Phosphate) into each of the wells. This plate was allowed to incubate for 15 minutes at $27^{\circ} \mathrm{C}$ in the dark. Finally, the reaction was stopped with $100 \mu \mathrm{l} /$ well of stop solution and the optical density (OD) was measured at $405 \mathrm{~nm}$ using ELISA reader. Based on the manufacturer's instruction, the validity of the test was based on the mean negative control (Mean NC) $O D<0.3$ and the difference between Mean NC OD and mean positive control OD $>0.15$.

\section{Statistical analysis}

GraphPad Prism 5.0 (GraphPad, USA) was used for descriptive and inferential statistical analysis. Fisher's exact test was used to determine IBV antibody relationship based on States, birds species and other variables. Univariate analysis within each variables was also carried out. The interpretation was considered significant at $p<0.05$.

\section{RESULT}

\section{Sampled birds}

Two hundred and sixty one birds were sampled with 43 (16.5\%) wild birds and 218 (83.5\%) indigenous (local) chickens (Gallus gallus). The wild birds consist of six each of Anas sparsa (water duck), Pavo cristatus (Indian peafowl) and Numidia meleagris (helmeted guinea fowl); four each of Dendrocygna viduata (white-faced whistling duck), Columba livia (rock dove/ pigeon) and Porphyrio madagascariensis (pukeko/African swamphen); three each of Anser domesticus (Emden goose), Trigonoceps occipitalis (white-headed vulture) and Balearica regulorum (grey crowned crane); two Leptoptilos crumeniferus (marabou stork), one Hieraaetus pennatus (booted eagle) and one Ciconia ciconia. All the birds in this study spread across 6 orders, 9 families and 14 species.

\section{Interview and distance observation}

The interview showed that all the local birds were reared under semi-intensive and extensive systems of management while both local and captive wild birds were never vaccinated against infectious agents. Also, local chickens were notably observed to scavenge within the communities and surrounding bushes. In addition, it was observed that only water duck scavenge within the zoo, but others, with the exception of white-headed vultures, do so within their cages. In some wild bird holdings, there were close communication between scavenging local chickens and wild birds in captive with the exception of pigeons and white-headed vultures. Some of the local chickens and captive wild birds laid small and roughened shell eggs with high infertility and poor hatchability. The interview result showed that newly acquired wild birds were usually quarantined before introducing to the existing flock, but screening for infectious diseases (past and present infections) was rarely done.

\section{IBV seroprevalence and univariate analysis result}

An overall IBV seroprevalence rate of $42.9 \%$ (112/261) was obtained in this study (Table 1 and 2). Captive wild birds and indigenous local chickens had IBV seroprevalence of $11.6 \%$ $(5 / 43)$ and $49.1 \%$ (107/218) respectively. Amongst these captive wild birds, only Trigonoceps occipitalis $33.3 \%(1 / 3)$, Columba livia $25 \%$ (1/4), Dendrocygna viduata $25 \%$ (1/4), Anas sparsa $16.7 \%(1 / 6)$ and Numidia meleagris $16.7 \%(1 / 6)$ had antibodies against IBV. Seroprevalence of IBV in the 3 states ranged between $31.3-66.3 \%$ with Kwara State having the highest prevalence $(66.3 \%, 53 / 80)$ followed by Oyo State $(50 \%, 29 / 58)$ and Osun State $(31.3 \%, 25 / 80)$. Based on sex, male birds had higher seroprevalence of IBV (50.0\%) than the female ones. Among local chickens, cock had the highest seroprevalence $(58.9 \%$, $43 / 73$ ) followed by grower (55\%) and hen (40\%). Also, when feather pattern of local chicken was considered, naked-neck chickens had the highest IBV seroprevalence $(7.7 \%, 21 / 31)$ followed by smooth $(52.7 \%, 68 / 129)$ and rough $(31 \%, 18 / 58)$ feathered chickens. Table 3 indicated that local chickens in this study had higher IBV antibody titer (7000.3147 \pm 1381.567$)$ than captive wild birds ( $3462.7047 \pm 3987.303$ ) (Table 3$)$. Among the State, Osun state had the highest IBV mean antibody titer (9863.1214 \pm 3338.685$)$ while Oyo state had the least $(2789.7882 \pm 1075.817)$.

A significant difference of the presence of IBV antibody was found between local chickens and captive wild birds ( $p<0.0001, O R=7.3,95 \% \mathrm{Cl}=2.8-19.3)$. However, within bird species, significance difference was found Pavo cristatus (Indian pea fowl) and Gallus gallus (Local chicken) $(p=0.03)$. The difference of being positive to IBV antibody among local chickens from Kwara $(p<0.0001, O R=4.3,95 \% \mathrm{Cl}=2.2-8.4)$ and Oyo $(\mathrm{P}=0.03, \mathrm{OR}=2.2,95 \% \mathrm{Cl}=1.1-4.4)$ states were significant

Table 1. Univariate analysis of Avian coronavirus (IBV) antibody based on bird species

\begin{tabular}{|c|c|c|c|c|c|c|}
\hline Order & Family & Scientific name & Freq. & IBV Positive (\%) & OR $(95 \% \mathrm{Cl})$ & p-value \\
\hline Galliformes & Phasianidae & Gallus gallus (Local chicken) & 218 & $107(49.1)$ & $1 !$ & \\
\hline Anseriformes & Anatidae & $\begin{array}{l}\text { Anas sparsa (Water duck) } \\
\text { Dendrocygyna viduata (White-faced whistling duck) } \\
\text { Anser domesticus (Emden goose) }\end{array}$ & $\begin{array}{l}6 \\
4 \\
3\end{array}$ & $\begin{array}{l}1(16.7) \\
1(25.0) \\
0(0.0)\end{array}$ & $\begin{array}{l}0.2(0.0-1.8) \\
0.3(0.0-2.4) \\
x\end{array}$ & $\begin{array}{l}0.2142 \\
0.3706 \\
0.2473\end{array}$ \\
\hline Galliformes & Phasianidae & Pavo cristatus (Indian pea fowl) & 6 & $0(0.0)$ & $x$ & $0.0301 *$ \\
\hline Galliformes & Numididae & Numidia meleagris (Helmeted guinea fowl) & 6 & $1(16.7)$ & $0.2(0.0-1.8)$ & 0.2142 \\
\hline Columbiformes & Columbidae & Columba liviai (Rock dove/pigeon) & 4 & $1(25.0)$ & $0.3(0.0-2.4)$ & 0.3706 \\
\hline Gruiformes & Rallidae & Porphyrio madagascariensis (Pukuko/African swamphen) & 4 & $0(0.0)$ & $x$ & 0.1226 \\
\hline Accipitriformes & Accipitridae & $\begin{array}{l}\text { Trigonoceps occipitalis (White-headed vulture) } \\
\text { Hieraaetus pennatus (Booted eagle) }\end{array}$ & $\begin{array}{l}3 \\
1\end{array}$ & $\begin{array}{l}1(33.3) \\
0(0.0)\end{array}$ & $\begin{array}{l}0.3(0.0-3.4) \\
x\end{array}$ & $\begin{array}{l}0.6221 \\
1.0000\end{array}$ \\
\hline Gruiformes & Gruidae & Balearica regulorum (Grey crowned crane) & 3 & $0(0.0)$ & $x$ & 0.2473 \\
\hline \multirow[t]{2}{*}{ Ciconiiformes } & Ciconiidae & $\begin{array}{l}\text { Leptoptilos crumeniferus (Marabou stork) } \\
\text { Ciconia ciconia (White stork) }\end{array}$ & $\begin{array}{l}2 \\
1\end{array}$ & $\begin{array}{l}0(0.0) \\
0(0.0)\end{array}$ & $\begin{array}{l}x \\
x\end{array}$ & $\begin{array}{l}0.4981 \\
1.0000\end{array}$ \\
\hline & & Total & 261 & 112 (42.9) & & \\
\hline
\end{tabular}

Key: ! Reference value OR- Odd ratio $95 \% \mathrm{Cl}-95 \%$ Confidence interval $\quad *$ Significance at $\mathrm{p}<0.05 \quad \mathrm{x}$ - Undetermined 
Table 2. Univariate analysis of Avian coronavirus (IBV) antibody in indigenous chickens and captive wild birds from Kwara, Osun and Oyo States Nigeria

\begin{tabular}{|c|c|c|c|c|}
\hline Features & Freq. (\%) & IBV Positive (\%) & OR $(95 \% \mathrm{Cl})$ & $\mathrm{p}$-value \\
\hline \multicolumn{5}{|l|}{ Bird Type } \\
\hline Local chickens & 218 & 107 (49.1) & $7.3(2.8-19.3)$ & $<0.0001^{*}$ \\
\hline Wild birds & 43 & $5(11.6)$ & 1 & \\
\hline \multicolumn{5}{|l|}{ aState } \\
\hline Kwara & 80 & $53(66.3)$ & $4.3(2.2-8.4)$ & $<0.0001^{*}$ \\
\hline Oyo & 58 & $29(50.0)$ & $2.2(1.1-4.4)$ & $0.034 *$ \\
\hline Osun & 80 & $25(31.3)$ & 1 & \\
\hline \multicolumn{5}{|l|}{ Sex } \\
\hline Male & 90 & $45(50.0)$ & $1.6(0.9-2.6)$ & 0.1143 \\
\hline Female & 171 & $67(39.2)$ & 1 & \\
\hline \multicolumn{5}{|l|}{ aBird class } \\
\hline Cock & 73 & $43(58.9)$ & $2.2(1.2-4.0)$ & $0.0150 *$ \\
\hline Grower & 40 & $22(55.0)$ & $1.8(0.9-3.8)$ & 0.1345 \\
\hline Hen & 105 & $42(40.0)$ & 1 & \\
\hline \multicolumn{5}{|l|}{${ }^{\text {a} F e a t h e r ~ T y p e ~}$} \\
\hline Naked-neck & 31 & $21(67.7)$ & $4.7(1.8-11.9)$ & $0.0015 *$ \\
\hline Smooth & 129 & $68(52.7)$ & $2.5(1.3-4.8)$ & $0.0070^{*}$ \\
\hline Rough & 58 & $18(31.0)$ & 1 & \\
\hline
\end{tabular}

Key: ${ }^{a}$ Only Chickens were considered $\quad *$ Significant at $\mathrm{p}<0.05$

Table 3. Mean and standard error of mean of Avian coronavirus (IBV) antibody titer using Enzyme linked immunosorbent assay

\begin{tabular}{lcc}
\hline FEATURES & IBV POSITIVE $(\%)$ & Titer Mean \pm SEM \\
\hline Local chicken & $107(49.1)$ & $7000.3147 \pm 1381.567$ \\
Osun & $25(31.3)$ & $9863.1214 \pm 3338.685$ \\
Kwara & $53(66.3)$ & $7953.8072 \pm 1975.789$ \\
Oyo & $29(50.0)$ & $2789.7882 \pm 1075.817$ \\
Wild birds & $5(11.6)$ & $3,462.7047 \pm 3987.303$ \\
\hline
\end{tabular}

Key: SEM- Standard error of mean

when compared independently with observations in Osun State. Among the local chickens, IBV seroprevalence significant difference was found between cock and hen $(p=0.015, O R=2.2,95 \% \mathrm{Cl}=1.2-4.0)$. Seroprevalence of naked-neck $(p=0.0015, O R=1.8-11.9)$ and smooth $(P=0.007$, $\mathrm{OR}=2.5,95 \% \mathrm{Cl}=1.3-4.8)$ feathered chickens in this study were found to be statistically significant when each were compared with that in rough feathered chickens.

\section{DISCUSSION}

The overall IBV seroprevalence in this study was $42.9 \%$ (112/261) with indigenous local chickens having higher IBV seroprevalence $(49.1 \%, 107 / 218)$ than captive wild birds $(11.6 \%, 5 / 43)$. Since these birds were not vaccinated, it implies that these birds were naturally exposed to IBV. The IBV seroprevalence of $66.3 \%$ among local chickens in Kwara State (North central Nigeria) was higher than $18.8 \%$ reported by Shettima et al. (2016) in Maiduguri metropolis (North central Nigeria). However, the prevalence obtained for Oyo state in this study (50\%) was lower than $78.32 \%$ reported by Emikpe et al. in 2010 in the same location. Generally, the prevalence among local chickens in this study (49.1\%) was higher than $21.2 \%$ reported in Ghana (Ayim-Akonor et al., 2018) but lower than $74.9 \%$ reported in Ethiopia among unvaccinated backyard chickens (Tesfaye et al., 2019). This cross-country seroprevalence differences might have resulted from varying environmental factors (which could mitigate the spread of IBV among local chickens), availability and use of IBV vaccine and hygiene practise.

The seroprevalence among captive wild birds (11.6\%) in this study was lower than $28 \%$ reported among those that were obtained in Bauchi, Gombe and Kaduna States of Nigeria (Musa et al., 2017). The IBV exposure of Anas sparsa (Water duck), Dendrocygyna viduata (White-faced whistling duck), Numidia meleagris (Helmeted guinea fowl), Columba liviai (Rock dove/pigeon) and Trigonoceps occipitalis (White-headed vulture) in this study further corroborated earlier reports of exposure and possible susceptibility among wild birds (Shittema et al., 2016; Musa et al., 2017).

Furthermore, significance difference was obtained in IBV seropositivity when local chickens from Kwara $(p<0.0001)$ and Oyo $(p=0.034)$ states were compared independently to that in Osun State. In addition, analysis showed that local birds in Kwara and Oyo States were 4.3 and 2.2 times respectively more likely to be exposed to IBV when compared to that in Osun State. Also, based on bird class, cocks' (local chicken) exposure to IBV was significantly higher than hens' $(p=0.015)$ with analysis that cocks were 2.2 times more likely to be exposed when compared with hen. Seroprevalence of IBV in both naked-neck and smooth-feather local chickens were both significantly different from rough-feather local chicken and analysis further indicated that naked-neck and smooth feathered local chickens were 4.7 and 2.5 times more likely to have been exposed when compared with roughfeather chickens. The reason for the exposure disparity to IBV based on feather type may not be easily determined. However, it might be that rough-feather chickens were less susceptible to IBV when compared with smooth-feather and naked-neck chickens. A deep investigation could illuminate the reason for this significant differences.

Ingestion of contaminated faeces by scavenging chickens reared locally seems to be the major exposure route of IBV infection. It has been observed that local chickens which are kept under extensive management systems have access to both humans and animal (both domestic and wild) wastes during their search for food (Daodu et al., 2020). The result of this could have been precipitated frequent underreported IBV cases revealed in our interview. 
Furthermore, the exposure to wild IBV could likely be one of the reasons for the low egg production among indigenous local chickens and captive wild birds when compared with exotic birds in commercial poultry production.

Despite their hardy nature and ability to survive in harsh tropical conditions, local chickens were yet exposed to infectious agents because of poor management system. Apart from poor production and attending mortalities resulting from this system, local chicken stands chance of spreading viruses and other infectious agents, as long as they have access, to commercial poultry and captive wild birds in zoos, private menageries and resorts. In addition, IBV infection could compromise some wild birds' productivity in such a way that they might not be able to be conserved (morbidity/ mortality) and multiplied (poor egg quality and infertility) as desired. The limitation in this study was the inability to use ELISA kit specific for detection of IBV IgG in each bird species considered.

Furthermore, quarantine should not be the only measures to prevent transmission of infectious agents from newly acquired wild animal, it is important that screening for infectious agents (zoonotic and non-zoonotic) should be assayed since humans (workers, visitors and tourists) and other wild animals would have access to such new animal.

\section{CONCLUSION}

This study confirmed that captive wild birds and local chickens from Kwara, Osun and Oyo States were exposed to infectious bronchitis virus. Also, the IBV exposure rates among local chickens in study locations (States) varied significantly. Several IBV risk factors were identified for both captive wild birds and local chickens. Wild bird management operations should be constantly reviewed and updated for an optimum standard practise for profit and public health safety. Also, local chicken keepers should harness available poultry vaccines to avoid unnecessary losses.

\section{ACKNOWLEDGEMENTS}

The authors wish to acknowledge the cooperation and permission granted by owners of the indigenous chickens and captive wild birds used in this study. Also, we appreciate the Director of Veterinary Teaching Hospital, University of Ilorin, Dr J.O Ayeidun, who gave us free access to the use of equipment within the facilities. We further recognised the assistance of Mr Shafi of the Microbiology Unit.

\section{Conflict of Interest}

This research did not receive any specific grant from funding agencies in the public, commercial, or not-for-profit sectors.

\section{REFERENCES}

Ayim-Akonor, M., Owusu-Ntumy, D.D., Ohene-Asa, H.E., OduroAbrokwa, A., Hammond, P., Appenteng, M. \& Annan, D. (2018). Serological and Molecular Surveillance of Infectious Bronchitis Virus Infection in Free-Range Chickens and Guinea Fowls in the Ga-East District of Ghana. Journal of Veterinary Medicine, 2018: 1-6. https:// doi.org/10.1155/2018/4949580

Daodu, O.B., Jegede, H.O., Aiyedun, J.O., Oludairo, O.O., Olorunshola, I.D., Daodu, O.C., Ajadi, A. \& Ambali, S.F. (2020). Surveillance for avian influenza virus in captive wild birds and indigenous chickens in Nigeria. Tropical Animal Health and Production 52: 2387-2393. https://doi.org/ 10.1007/s11250-020-02265-y
Emikpe, B.O., Ohore, O.G., Olujonwo, M. \& Akpavie, S.O. (2010). Prevalence of antibodies to infectious bronchitis virus (IBV) in chickens in southwestern Nigeria. African Journal of Microbiology Research 4(1): 92-95.

Jackwood, M.W. (2019). Infectious Bronchitis in Poultry. In: Merck Veterinary manual 2019. https://www.merckvet manual.com/poultry/infectious-bronchitis/infectiousbronchitis-in-poultry?query=infectious bronchitis virus

MacLachlan, N.J. \& Dubovi, E.J. (2011). Coronaviridae. In: Fenner's Veterinary Virology, 4th edition. Academic press, pp. 394-413.

Milek, J. \& Blicharz-Domańska, K. (2018). Coronaviruses in avian species - review with focus on epidemiology and diagnosis in wild birds. Journal of Veterinary Research 62: 249-255. https://doi.org/10.2478/jvetres-2018-0035

Musa, W.I., Abdullah, B.Y., Lawal, S., Bello, M. \& Abdu, P.A. (2017). Detection of antibodies to avian influenza, infectious bronchitis and Newcastle disease viruses in wild birds in three states of Nigeria. Sokoto Journal of Veterinary Science 15: 28-35. https://doi.org/10.4314/ sokjvs.v15i4.5

Tesfaye, A., Kassa, T., Mesfin, S., Garoma, A., Koran, T., Dima, C., Guyassa, C., Hailu, H. \& Teshale, S. (2019). Four Serotypes of Infectious Bronchitis Virus are Widespread in Unvaccinated Backyard Chicken and Commercial Farms in Ethiopia. World Journal of Veterinary Science 1(1): 1001. https://doi/org/10.3390/vetsci7040187

Woo, P.C., Lau, S.K., Huang, Y. \& Yuen, K.Y. (2009). Coronavirus diversity, phylogeny and interspecies jumping. Experimental Biology and Medicine (Maywood) 234: 1117-1127. https:// doi.org/10.3181/0903-MR-94 